\title{
Different Approaches to Enantiosemy in English
}

\author{
Hasmik Kajberuny, Tamara Hakobyan \\ Yerevan Brusov State University \\ of Languages and Social Sciences
}

\begin{abstract}
Our interest in this article is to investigate different approaches to enantiosemy in English. In the coverage of a variety of viewpoints introduced in the present article, reference is made to well-established traditional and most recent perspectives and approaches provided by both European and Russian scholars with the view of elucidating different principles of classification.

The data for the analysis are extracted from different dictionaries and British National Corpus in order to find distinct motivated meanings between opposite senses in the semantic structure of enantiosemic words. The analysis of the data enables us to reveal some regularities of antonymic relations which make it possible to regard them as special cases of polysemy in English.

For this reason we consider it crucial to disclose integral and differentiating semes, as well as different potential semes, which give rise to different associations.
\end{abstract}

Key words: enantiosemy, homonymy, polysemy, integral semes, differentiating semes, hyperlexeme, collocation, irony, derivation.

\section{Introduction}

The phenomenon of linguistic opposition has become the subject of linguistic investigation due to its being the potential extension of the form-meaning range of relations. In the English language up to now the problem of linguistic opposition has been researched in the sphere of antonymic and antisemic units. But on the lexical level of language, there is one more type of opposition, 
namely - the enantiosemic one, i.e. the polarization of meanings within one lexical unit.

The term "enantiosemy" was first introduced by the Czech philologist V.I. Shertsl in his article "On the issue of words with opposite meanings/ or the so called enantiosemy" (Shertsl 1883:1-39).

Concise Oxford dictionary of linguistics defines the term as a case of polysemy in which one sense is in some respect the opposite of another (Concise Oxford Dictionary of Linguistics 2014).

Dictionary of Linguistic terms by O.S. Akhmanova defines enantiosemy as polarization of meanings, the ability of the word (morpheme, etc.) to express antonymic meanings (Akhmanova 1966:517).

It stands to reason, that in the course of the historical development of language the process of clarification of different notions took place, which resulted in differentiation of meanings. The latter stemmed from reinterpretation of ideas, critical perception of reality right up to the opposite perception of one and the same phenomena. It resulted in the usage of words ironically and the possibility of regarding one and the same phenomena from different angles. Multiple associations related to different phenomena make it possible to disclose the unity of opposite but interconnected processes and phenomena which find their reflection in enantiosemy.

Different approaches were singled out regarding the linguistic status of enantiosemy.

According to some linguists (A.N. Novikov; V.N. Prokhorova, V.V. Vinogradov; Y.V. Terentyeva; N.M. Shanski) enantiosemy is considered to be a case of homonymy and the latter is first and foremost accounted for by the fact that polar meanings of enantiosemic words are identical in sound form and spelling by virtue of convergent evolution of words (Makhmutova 2009:266). A vivid example of an enantiosemic word is "to cleave" which means "to split and to adhere". In its original meaning - "to split, part or divide by force", "cleave" was borrowed from Old English "cleofan, cleven, cliven". The opposite meaning of the word "cleave" - "to adhere, cling" was borrowed from Middle English "cleven, clevien, cliven", from Old English "clifian, cleofian”. 
Meanwhile, some linguists (F.S. Batsevich; L.Ye. Bessonova; N.K. Salikhova; O.I. Smirnova, V.Yu. Kravtsova; A. Klegr; A.D. Shmelev) regard enantiosemy as a case of polysemy in which one sense is in some respect the opposite of another (Makhmutova 2009:266). The latter arises from semantic shifts when the meaning of a sign takes two different forms resulting in the formation of two opposite meanings. We adhere to the opinion of those linguists who regard enantiosemy as a special case of polysemy (Klegr 2013:13).

As the linguists rightly mention, there are good reasons to exclude cases of homonymy from enantiosemy. Antonymous homonyms being by definition entirely accidental are of no real interest semantically as there is nothing to relate to them intrinsically. By contrast, the relation between antonymous polysemes must be semantically motivated and so at least part of them may be expected to display recurrent features which should make it possible to divide them into different categories. Hence, enantiosemy can be regarded as a regular case of polysemy as at least some of its types exhibit a systematic relation to its diametrical opposite sense. The possibility of finding a semantic connection between the enantiosemy and another polysemy and the feeling of unity which binds the different senses of a word together seem to argue for the hyperlexeme interpretation.

\section{Different Principles of Classifications of Enantiosemy in English}

The analysis of the semantic structure of lexical units under study has revealed some regularities of antonymic relations which make it possible to single out different classifications of enantiosemy in English.

According to Czech linguist A. Klegr, the opposition results from "vectorial", directional differentiation of the senses of the lexeme which then become "reversives". They include verbs formed by conversion from nouns which function as the pivotal components of the activity concerned (e.g. milk, dust, seed, shell, skin, stone). The most frequent type is the opposition "to remove/deprive of" versus "to add/yield" as, for example, in "to skin" - to strip or deprive of skin, to scrape skin from; to cover with skin (Klegr 2013: 14). 


\section{Dust (v.)}

1. to remove dust from surface, remove dirt

e.g. Two weeks ago we were given hand brushes to dust the machines in front of us. (BNC)

2. to cover sth. with fine powder

e.g. We continued our work until the fingerprint man arrived to dust that dreadful black powder everywhere. (BNC)

\section{Skin (v.)}

1. to remove skin from

e.g. Before skinning an animal, examine the carcass and make sure that the fur is clean and free from foreign matter. (BNC)

2. to cover with a skin or a similar layer e.g. He skinned the framework of a canoe. (BNC)

It is now universally recognized that although objective reality exists outside human beings, every language classifies reality in its own way by means of vocabulary units.

Of great importance is the investigation of lexical restrictions on collocability that are of purely linguistic nature. Thus, as can be inferred from the above, collocational enantiosemes include lexical units in which a given sense lends itself to alternative interpretations depending on the semantics of the collocators (the object, the governing verb, etc.) they combine with (Klegr 2013: 15).

The analysis of numerous lexical units under study extracted from dictionaries and corpus based data testify to their frequency of occurrence in different collocations.

Aggressive (adj.)

1. Aggressive attack - angry or behaving in a threatening way; ready to attack

e.g. Supervisors who use aggressive behavior to dominate and control staff are among the most difficult for an employee to deal with. (BNC) 
2. aggressive efforts - behaving in a very determined and forceful way in order to succeed e.g. Clydesdale Electrical ... which has shown impressive growth ..., won the judges' unanimous approval for its courageous and aggressive marketing strategy. (BNC)

Habitual (adj.)

1. Habitual response - usual or typical e.g. If we are ever to change our habitual response to given stimuli we have to make a conscious decision to refuse to act in old automatic and unconscious patterns. (BNC)

2. Habitual criminal, habitual drinker, habitual liar - done in a way that is annoying or difficult to stop

e.g. Blood alcohol levels rise at pretty much the same rate in infrequent and habitual drinkers. (BNC)

The semantic shift based on irony through repeated use becomes permanently associated with a given lexeme and subsequently appears in dictionaries as one of the senses of lexeme (Klegr 2013: 16). The ironic sense is signalized pragmatically (by a contrast between the notional and the contextual meaning). Irony is a relatively frequent source of enantiosemy. The fact that mostly all of these examples are found in dictionaries may be taken as a sign of their lexicalization. The result of ironic use of a word or utterance is the emergence of an opposite meaning which is determined in context.

$\operatorname{Bomb}($ n.)

1. (AmE, informal) an absolute failure e.g. The last play was a bomb, the hall was almost empty. (BNC)

2. (BrE) to be very successful (with definite article "the") e.g. Their new record is the bomb. (BNC) 
Precious (adj.)

1. Valuable, very costly

e.g. This is a precious book, in both senses of the word: a delightful thing of value, and overly affected.(Fine Dictionary)

2. (informal) worthless

e.g. All of a sudden he shouted, "you and your precious ideas". (BNC)

\section{Emotive-evaluative Enantiosemy}

Guided by the principles of classifying enantiosemic words suggested by A. Klegr, we made an attempt to probe deeper into the phenomena of enantiosemy with the view of revealing the component of linguistic evaluation.

It is worth mentioning that the tendency towards the revision of old norms in some cases displays rational impartial (nominative) character of enantiosemy. Opposite meanings may arise for expressions that refer to something obvious: they may imply that something is evident and beyond doubt or, on the contrary, that it only appears to be so and that things are totally different in reality.

Apparent (adj.)

1. evident, obvious: apparent effort, apparent error e.g. The apparent indifference seems to have spread to Lendl's attitude to the remainder of this year. (BNC)

2. seeming, ostensible, obscure: apparent innocence, apparent cause e.g. Yet I always questioned whether this separation was not more apparent than real. (BNC)

Implicit (adj.)

1. not explicit; implied; indirect: implicit criticism e.g. The second aspect seems even more important: it warns against false generalizations and implicit assumptions. (BNC) 
2. absolute, unreserved; unquestioning: implicit trust e.g. He had implicit trust in the righteousness of the 'movement', and was eager to carry out the orders of its leader. $(B N C)$

Alongside with the nominative character of enantiosemy, emotiveevaluative enantiosemy presents special interest regarding the fact that evaluative enantiosemy in the semantic structure of polysemantic words finds its reflection both in differential and potential semes revealing all possible associations.

Actually, the acquisition by the word evaluative connotation is mostly conditioned by the national tradition, i.e., by the tendency to ascribe negative or positive features to different objects of reality, in accordance with the national aesthetic perception and value system (Retunskaya 1996:40).

Numerous examples adduced from dictionaries and British National Corpus come to prove that a very large group of lexical units displaying emotiveevaluative enantiosemy refers to the duality of human nature, their emotions and attitude to reality, as well as the re-evaluation of moral values.

\section{Self-conscious (adj.)}

1. embarrassed or nervous about your appearance or what other people think of you.

e.g. He seemed suddenly to have become more awkward and self-conscious. (BNC)

2. confident, (often disapproving) done in a way that shows you are aware of the effect that is being produced

e.g. The self-conscious actor kept fixing his hair, admiring his image in the mirror. (Merriam-Webster Dictionary and Thesaurus) 
Shark (n.)

1. (disapproving) a person who is dishonest in business, especially sb. who gives bad advice and gets people to pay too much for sth.

e.g. Property sharks want to develop 200 acres around the site. (Fine Dictionary)

2. an expert in a specified field e.g. Paig Taylor's attorney, Alan Penn, was Venable's opposite, a compact, energetic shark, who had built a reputation for racking up acquittals for his clients. (Sheldon 1995:3)

Lofty (adj.)

1. (formal) of a high moral standard: lofty ideas e.g. It was a bank that started out with grand ideas and lofty ideals. (Collins English Dictionary)

2. (disapproving) pompous, arrogant, haughty a lofty attitude/air/tone e.g. Other blue sky thinkers in Palo Alto have similarly lofty ambitions.

Pious (adj.)

1. having or showing a deep respect for God and religion e.g. Eric spoke of the beautiful and genuinely pious conduct of the priest towards the prisoners. (BNC)

2. disapproving: pretending to be religious, moral or good in order to impress other people

e.g. White lies are verbal cases of pious fraud. (BNC)

Awesome (adj.)

1. rather frightening, inspiring awe, very difficult e.g. In passages written not without humour, though theirs is the blackest of black comedy, we read of the water of the Nile turned to blood, of plagues of frogs, gnats, flies, and locusts, of the domestic animals of the Egyptians dying of disease, of a 
terrible outbreak of boils, of death-dealing hailstorms, and an awesome and fearful darkness. (BNC)

2. informal: extremely good; excellent, enjoyable: awesome beauty e.g. I turned and shouted the discovery to Miller and Brown, who toiled up beside us to stare at the awesome beauty of the Peak in dull wonderment. (BNC)

As can be seen from the examples adduced above, the lexical items under study can be utilized ironically or can bear disapproving sense.

\section{Derivational Enantiosemes}

It is interesting to note that the process of re-interpretation of ideas, notions and moral values finds its reflection in the derivational system of the English language. It presents special interest in regard to derivational enantiosemy. The latter is conditioned by the fact that the investigation of recurrent antonymic semes in the polysemantic words makes it possible to disclose the English national language creativity mechanisms.

In English a great number of the lexical units and their derivatives undergo the process of semantic extension. Moreover, there is a strong tendency for the vocabulary of the English language to undergo the process of further semantic extension, thus reflecting different aspects of reality by means of the same lexical units.

Vis a vis the perspectives of our analysis we have revealed some regularities which are typical of the English word building system. Of special interest are lexical units that, apart from their meaning, convey some additional information and, thus, comprise some elements of evaluation in them.

The study of the data extracted from both dictionaries and corpus based data reveals different types of relationship between motivating bases and their derivatives:

a. The motivating bases lack any evaluative meaning while their derivatives have undergone the process of semantic 
derivation. We have singled out derivatives bearing both positive and negative evaluation.

Moral (adj.) - concerned with principles of right and wrong behavior: a moral issue/dilemma/ question.

Moralize (v.)

1. (disapproving) to tell other people what is right or wrong, in order to emphasize that your ideas are correct.

e.g. Stop moralizing about the principles you never follow. (BNC)

2. to explain in a moral sense

e.g. This fable is moralized in a common proverb. (Fine Dictionary)

Rope (n.) - very strong thick string Ropy(adj.)

1. in bad condition, of low quality: ropy tyres

e.g. He had to change the ropy tyres to avoid car accident. (BNC)

2. strong, tough, like a rope: ropy muscles

e.g. The ropy muscles in their arms bulge out like India rubber balls. (BNC)

b. both motivating bases and their derivatives display antonymic semes as a result of further semantic stretching.

Collaborate (v.)- 1.To work together, cooperate; 2.To cooperate with an enemy

Collaborator (n.)

1. co-worker, partner, colleague, associate, team-mate, confederate e.g. He was a friend, a confidant, an adviser, a business manager, a collaborator. (BNC) 
2. traitor, turncoat, quisling, collaborationist, fraternizer e.g. Gunman admits Nazi killing A LONE gunman killed a French Nazi collaborator yesterday, and then went on television to claim responsibility. (BNC)

Demon (n.) - 1. An evil spirit; 2. skillful, energetic, a person who does something very well with a lot of energy,

Demonic (adj.)

1. coming from or belonging to a demon or being like a demon: demonic forces, a demonic grin.

e.g. He needs not to forget that there are demonic forces in the universe whatever people say about the existence of the devil. (BNC)

2. energetic, determined, or clever than most people. e.g. ... But let us take another view of this perfectionism that Karajan is accused of, with another quotation: Certainly, many have extolled his demonic personality, his unheard-of sense of style, the precision of his performances as well as their tonal beauty and clarity. (BNC)

Of considerable significance in this respect is the fact that figurative meanings of enantiosemic words, such as shark, monster, demon, can serve as key words for depicting characters in the text.

We have applied a two-level analysis, i.e. the definitional analysis and the contextual analysis. The former makes it possible to reveal the inner mechanisms which function within the language system, namely, to reveal combinability rules of the lexical units under study and to disclose differential semes which serve as the basis for semantic stretching. The latter is to illustrate the actualization of different meanings of enantiosemic words in the context.

e.g. He was a monster of conceit. Never for one minute did he look at the world or at people, except in relation to 
himself. He was not only the most important person in the world, to himself; in his own eyes he was the only person who existed. He believed himself to be one of the greatest dramatists in the world, one of the greatest thinkers, and one of the greatest composers.

...He had a genius for making enemies. He would insult a man who disagreed with him about the weather. He would pull endless wires in order to meet some man who admired his work, and was able and anxious to be of use to him - and would proceed to make a mortal enemy of him with some idiotic and wholly uncalled-for exhibition of arrogance and bad manners.

...The name of this monster was Richard Wagner. (Taylor 2013)

The analysis of the words "demonic, monster" in different essays made it possible to single out two differential semes: on the one hand, the boundless creative energy, and, on the other hand, its destructive force, which like a monster or a demon is associated with evil personality. The study of the essays disclosing the duality of the nature of such eminent musicians as Karajan, Wagner throws light on their demonic personality versus their being musicians of genius.

Moreover, the differential and potential semes of the enantiosemic words bearing positive and evaluative connotation can serve as the basis for employing the stylistic device of irony in the texts.

e.g. ... the Gulf War on the basis that regimes which defy international law and slaughter innocent people must be confronted, no matter what the cost. Those of us who campaigned against the Gulf War did so not because we had any liking for Saddam Hussein... We argued that Western rulers had finally taken out against Saddam not because he 
was a monster but because he had broken loose and was no longer their monster. The monstrous behaviour of the Turkish regime towards the Kurds now, and the shifty, sinister silence of the West, proves the point. (BNC)

Thus, irony enantiosemes are exploited in such a way that their intended meaning is different from the actual meanings of the words.

\section{Conclusion}

To conclude, it can be noted that enantiosemy stems from re-interpretation of ideas, critical perception of reality, as well as the duality of human nature. The latter preconditions the viability of the phenomenon of enantiosemy.

Of special interest are the lexemes which convey both neutral and disapproving component in their semantic structure. In regard to the peculiarities of derivational enantiosemy, it is worth mentioning that we have revealed some regularities which are typical of the English word building system. Of great importance is the investigation of lexical restrictions on collacability of enantiosemic words that are of purely linguistic nature.

Shedding light on what concerns emotive-evaluative enantiosemy it should be noted that emotive-evaluative component in the semantic structure of polysemantic words can be revealed both in differential and potential semes. In the majority of cases the polarity of meaning is achieved by virtue of adding derivational affixes to the derivatives under study. The analysis of numerous lexical units under study extracted from dictionaries and corpus based data testifies to their frequency of occurrence in different collocations.

The ever increasing number of linguistic units conveying recurrent antonymic semes comes to prove the significance and topicality of the lexical items under consideration.

\section{References:}

1. Klégr, A. (2013) The Limits of Polysemy: Enantiosemy. // Linguistica Pragensi. Vol. 23. Praha: Filozofická Fakulta, UK v Praze. 
2. Kravtsova, V. Yu. (2006) Enantiosemiya leksicheskikh i frazeologicheskikh yedinits: (Yazik i rech). / Dis... PhD: 10.02.19: Rostov.

3. Makhmutova, L.R. (2009) Mesto enantiosemii v sisteme yazika. // Uchoniye zapiski Kazantskovo gosudarstvennovo universiteta. Tom 151. kn. 3: Gumanitarniye nauki.

4. Nechayev, A.A. (2014) Istochniki i vidi enantiosemii. // Molodoy uchoni, 6.

5. Retunskaya, M.S. (1996) Angliskaya aksiologicheskaya leksika. / Monografiya: N. Novgorod.

6. Shmelev, A. (2016) Semantic Shifts as Source of Enantiosemy.// The Lexical Typology of Semantic Shifts. / P. Juvonen, M. KoptjevskajaTamm. M.: Walter de Gruyter GmbH \& Co KG.

7. Shertsl, V.N. (1883) O slovakh s protivopolozhnimi znacheniyami (ili o tak nazivayemoy enantiosemii). // Filologicheskiye zapiski. 1883. Vip. 5-6. Available at: <https://fessl.ru/docsdownloads/09_16/RF/FILZAP.pdf> [Accessed September 2019].

\section{Sources of Data:}

1. Akhmanova, O.S. (1966) Slovar lingvisticheskikh terminov. M.: Sovetskaya entsiklopediya.

2. British National Corpus (BNC). Available at: <http://www.natcorp.ox.ac.uk> [Accessed August 2019].

3. Collins English Dictionary. Available at: <https://www. collinsdictionary.com $>$ [Accessed September 2019].

4. (2014) Concise Oxford dictionary of linguistics, 3rd edition. Oxford: OUP.

5. Conversations with Karajan (1991). / Osborne, Richard. Oxford: OUP.

6. Fine Dictionary, Dictionary with definitions from 4 dictionaries. Available at: <https://www.finedictionary.com> [Accessed September 2019].

7. Merriam-Webster Dictionary and Thesaurus. Available at: <http://www.merriam-webster.com> [Accessed September 2019].

8. (2010) Oxford Advanced Learner's Dictionary of Current English. Oxford: OUP.

9. Sheldon, S. (1995) Nothing Lasts Forever. / Harper Collins. 
10. Taylor, D. (2013) The Monster, Wagner Bicentennial Symposium. Available at: <https://www.counter-currents.com/2013/05/the-monster> [Accessed June 2019].

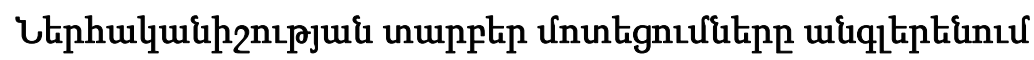

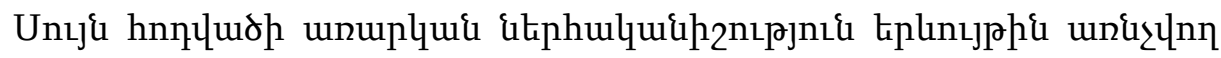

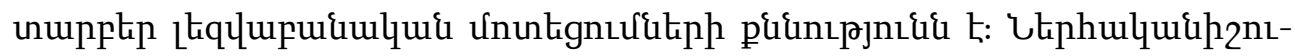

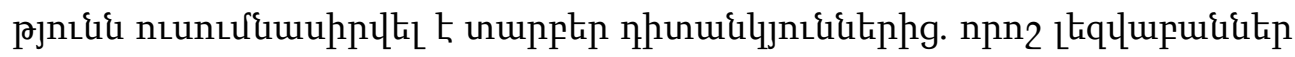

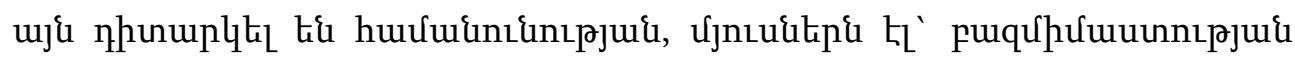

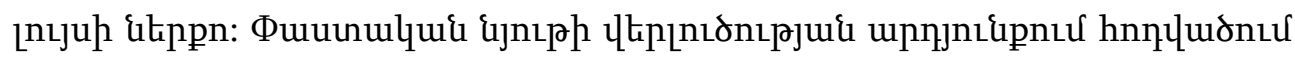

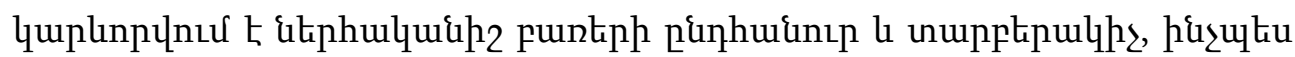

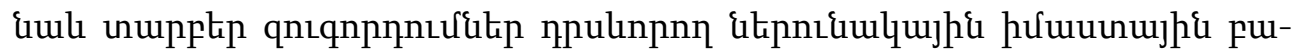

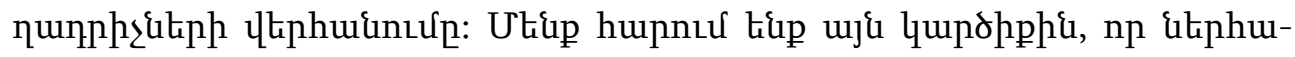

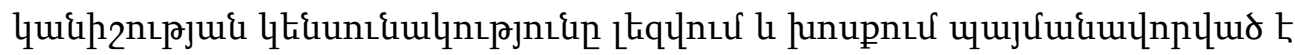
puquर्uरumunntpjuxu्u:

Received by the Editorial Board 06.09.2019

Recommended for publication by the reviewers 10.10.2019

Accepted for print 10.01.2020 